\title{
COMMENTARY
}

\section{What is the optimal rate of failed extubation?}

\author{
James S Krinsley*, Praveen K Reddy and Abid lqbal
}

\begin{abstract}
Failed extubation (FE), defined as reintubation 48 or 72 hours after planned extubation, occurs in a significant percentage of patients and is associated with a substantial burden of morbidity and mortality. This commentary reviews the literature describing FE rates and the clinical consequences of FE and proposes an 'optimal' rate of FE as well as avenues for future research.
\end{abstract}

\section{Introduction}

In patients presenting with right lower abdominal pain, fever, and leukocytosis, surgery is frequently performed for suspected appendicitis. However, in a large contemporary series, $6.4 \%$ of patients with suspected appendicitis had a normal appendix removed [1]. Surgeons with a significantly higher 'negative appendix' rate are likely operating too frequently, and those with rates approaching zero are almost certainly not operating on enough patients.

The decision regarding when to liberate patients from mechanical ventilation faces intensive care unit (ICU) clinicians regularly. While this decision is typically based on a variety of data, there is often considerable uncertainty about the success of extubation.

The decision of whether to operate on a suspected appendicitis has, as we shall see, some similaries with the decision of when to extubate. Failed extubation (FE), defined as the need for reintubation within 48 or 72 hours of planned extubation, occurring in $0 \%$ of patients would suggest that mechanical ventilation was continued for an unnecessarily long duration, and FE occurring in $50 \%$ would suggest that too many patients were liberated from mechanical ventilation prematurely.

What, then, is the optimal rate of FE? Moreover, does it matter? To help answer these questions, this commentary

*Correspondence: jkrinsley@stamhealth.org

Department of Medicine, Division of Critical Care, Stamford Hospital, 190 West Broad Street, Stamford, CT 06902, USA will review some of the literature on ventilator weaning trials to ascertain the reported range of $\mathrm{FE}$ as well as the more limited literature describing the clinical consequences of FE. Finally, we will attempt to answer the question posed by the title of this commentary and propose avenues for future investigation.

\section{What is the reported rate of failed extubation in the literature?}

Figure 1 displays the range of FE rates reported in interventional trials of weaning strategies and observational cohort studies. The mean (standard deviation) rates in interventional and observational studies are 15.7 (15.6) $(\mathrm{n}=55)$ and $15.0(14.0)(\mathrm{n}=96)$, respectively. (References are listed in the Supplemental file.) The rates vary widely in part because of differences in the diagnostic categories of the patients studied, the duration of mechanical ventilation prior to planned extubation, and the interventions that were assessed. An investigation by Esteban and colleagues [2] is perhaps the best known of the randomized trials. This multicenter study evaluated four methods of weaning patients from mechanical ventilation: intermittent mandatory ventilation, pressure support ventilation, intermittent spontaneous breathing trials throughout the day, and single spontaneous breathing trials. FE occurred in $13.8 \%, 18.9 \%, 15.2 \%$, and $22.6 \%$ of the patients, respectively [2]. More recently, Bien and colleagues [3] evaluated the predictive power of three contemporary methods of weaning: T-piece, automatic tube compensation, and pressure support ventilation in 68 consecutive medical ICU patients. The rate of FE for the cohort was $33.8 \%$.

\section{Clinical consequences of failed extubation}

A more limited literature describes the clinical consequences of FE. Thille and colleagues [4] prospectively evaluated all patients with planned extubation over the course of a year in a single medical ICU; FE occurred in $15.5 \%$. Patients with FE were older, had a more significant underlying cardiac disease, and were ventilated longer before planned extubation than were patients with successful extubation. Patients with FE sustained far higher rates of pneumonia within 72 hours after extubation $(27 \%$ versus $0 \%)$ and of death (50\% versus $5 \%)$ than did those with successful extubation. 


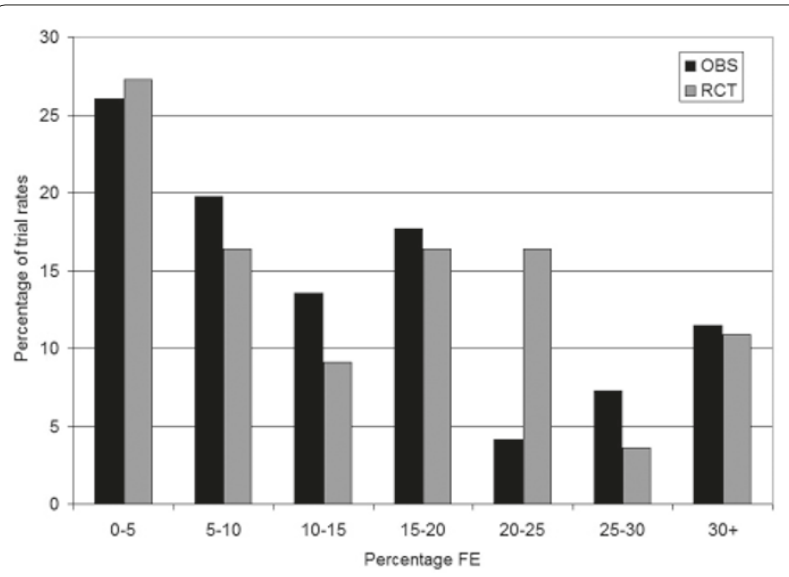

Figure 1. Rates of failed extubation in observational cohort studies and prospective randomized trials. FE, failed extubation; OBS, observational cohort study; RCT, randomized controlled trial.

We recently completed a case control study of FE [5]. Over a 5-year period, 2,012 patients received mechanical ventilation in our 16-bed medical-surgical ICU; 1,294 had a planned extubation. Eighty-five (6.6\%) sustained FE. The patients with FE were matched 1:3 with 255 control patients who were successfully extubated. Matching parameters included duration of ventilation before planned extubation, age, Acute Physiology Score, and admitting diagnosis to the ICU. Ventilator-associated pneumonia developed in $7.1 \%$ of the index patients with FE versus $0.8 \%$ of the controls with FE $(P=0.0043)$. ICU length of stay was considerably longer in patients with FE: 11.8 (7.7 to 17.5 ) versus 3.8 (2.1 to 7.5 ) days $(P<0.001)$. Mortality was more than twice as high: $23.5 \%$ versus $10.2 \% \quad(P=0.0052)$; multivariate analysis determined that FE was independently associated with increased risk of mortality: odds ratio of 2.64 (95\% confidence interval of 1.35 to 5.14$)(P=0.0044)$. These data suggest that, far from being inconsequential, FE is associated with a substantial burden of morbidity and mortality.

\section{Is there an optimal rate of failed extubation?}

The diversity of patient populations, study settings, and interventions evaluated precludes a clear-cut answer to this question on the basis of a review of the literature. Nevertheless, we believe that an FE rate of $14 \%$, the median rate observed in the interventional and observational studies described above, is inappropriately high.

A singular focus on lung mechanics characterizes the literature reporting FE rates. Typically, patients are deemed ready for liberation from mechanical ventilation when they have successfully passed a test, such as a spontaneous breathing trial with a low rapid shallow breathing index (expressed as the ratio of respiratory rate to tidal volume, or RR/Vt) [6]. In fact, the original study describing the use of this index reported an FE rate of $22 \%[6]$.

Perhaps the systematic inclusion of parameters not related to lung mechanics would yield lower rates of FE. In particular, these might include factors associated with the patient's general medical status, such as vital signs, neurologic status, nutritional status, and laboratory findings such as electrolyte abnormalities and anemia. In addition, greater attention to airway issues - secretion volume, purulence, viscosity, and the patient's ability to both 'clear' and 'protect' the airway if extubated - may further reduce the FE rate [7].

In fact, a systematic awareness of all three 'domains' of readiness for liberation from mechanical ventilation good 'performance' on the ventilator (positive endexpiratory pressure or continuous positive airway pressure of not more than 5 , good lung mechanics during spontaneous breathing trials or low level of pressure support ventilation, and ability to tolerate a fraction of inspired oxygen $\left(\mathrm{FiO}_{2}\right)$ of not more than 0.5$)$, good overall medical status, and the perceived ability of the patient to clear and defend the airway after extubation - by a small group of intensivists practicing in a protocol-driven environment in our mixed medical-surgical ICU has led to the $6.6 \%$ rate of $\mathrm{FE}$ and relatively short duration of intensive care noted above [5]. This number is remarkably close to the $6.4 \%$ rate of 'negative' appendectomies cited at the beginning of this commentary. Accordingly, while differences in patient populations and clinical practices undoubtedly complicate the choice of a single number, we choose the range of $5 \%$ to $10 \%$ as our proposed 'optimal' rate of FE.

\section{Conclusions}

FE occurs in a significant percentage of patients after planned extubation and is associated with significant morbidity and mortality. Efforts to evaluate, in a more systematic manner, factors beyond those related to pulmonary mechanics may lead to lower rates of FE without unnecessarily increasing the duration of mechanical ventilation. Future research exploring the differences in the 'three domains' of readiness for liberation from mechanical ventilation that distinguish patients who sustain FE from those who are successfully extubated may yield models that will assist clinicians in improving the outcomes of mechanical ventilation.

\section{Abbreviations}

FE, failed extubation; ICU, intensive care unit.

\section{Competing interests}

The authors declare that they have no competing interests. 
References

1. Güller U, Rosella L, McCall J, Brügger LE, Candinas D: Negative appendicectomy and perforation rates in patients undergoing laparoscopic surgery for suspected appendicitis. Br J Surg 2011, 98:589-595

2. Esteban A, Frutos F, Tobin MJ, Alía I, Solsona JF, Valverdú I, Fernández R, de la Cal MA, Benito S, Tomás R, Carriedo D, Macias S, Blanco J: A comparison of four methods of weaning patients from mechanical ventilation. N Engl J Med 1995, 332:345-350

3. Bien M, Lin Y, Shih C, Yang Y, Lin H, Bai K, Wang J, Ko Y: Comparisons of predictive performance of breathing pattern variability measured during T-piece, automatic tube compensation and pressure support ventilation for weaning intensive care unit patients from mechanical ventilation. Crit Care Med 2011, 39:2253-2262

4. Thille A, Harrois A, Schortgen F, Brun-Buisson C, Brochard L: Outcomes of extubation failure in medical intensive care unit patients. Crit Care Med 2011, 39:2612-2618

5. Krinsley J, Reddy P, lqbal A: Case-control study of failed extubation. Crit Care 2012, 16(Suppl 1):P128.

6. Tobin MJ, Perez W, Guenther SM, Semmes BJ, Mador MJ, Allen SJ, Lodato RF, Dantzker DR: The pattern of breathing during successful and unsuccessful trials of weaning from mechanical ventilation. Am Rev Resp Dis 1986 134:1111-1118.

7. Khamiees M, Raju P, DeGirolamo A, Amoateng-Adjepong Y, Manthous CA: Predictors of extubation outcome in patients who have successfully completed a spontaneous breathing trial. Chest 2001, 120:1262-1270.

\section{Supplemental file}

1. Peñuelas O, Frutos-Vivar F, Fernández C, Anzueto A, Epstein SK, Apezteguía C, González M, Nin N, Raymondos K, Tomicic V, Desmery P, Arabi Y, Pelosi P, Kuiper M, Jibaja M, Matamis D, Ferguson ND, Esteban A; Ventila Group: Characteristics and outcomes of ventilated patients according to time to liberation from mechanical ventilation. Am J Respir Crit Care Med 2011, 184:430-437.

2. Cheng KC, Chen CM, Tan CK, Chen HM, Lu CL, Zhang H: Methylprednisolone reduces the rates of postextubation stridor and reintubation associated with attenuated cytokine responses in critically ill patients. Minerva Anestesiol 2011, 77:503-509.

3. Khilnani GC, Galle AD, Hadda V, Sharma SK: Non-invasive ventilation after extubation in patients with chronic obstructive airways disease: a randomised controlled trial. Anaesth Intensive Care 2011, 39:217-223.

4. Stamou SC, Nussbaum M, Carew JD, Dunn K, Skipper E, Robicsek F, Lobdell KW: Hypoglycemia with intensive insulin therapy after cardiac surgery: predisposing factors and association with mortality. J Thorac CardiovasC Surg 2011, 142:166-173.

5. Sellares J, Ferrer M, Cano E, Loureiro H, Valencia M, Torres A: Predictors of prolonged weaning and survival during ventilator weaning in a respiratory ICU. Intensive Care Med 2011, 37:775-784

6. Cata JP, Saager L, Kurz A, Avitsian R: Successful extubation in the operating room after infratentorial craniotomy: the Cleveland Clinic experience. J Neurosurg Anesthesiol 2011, 23:25-29.

7. $\quad$ Ried M, Unger P, Puehler T, Haneya A, Schmid C, Diez C: Mild-to-moderate COPD as a risk factor for increased 30-day mortality in cardiac surgery. Thorac Cardiovasc Surg 2010, 58:387-391.

8. Narita M, Tanizawa K, Chin K, Ikai I, Handa T, Oga T, Niimi A, Tsuboi T, Mishima M, Uemoto S, Hatano E: Noninvasive ventilation improves the outcome of pulmonary complications after liver resection. Intern Med 2010, 49:1501-1507.

9. González M, Arroliga AC, Frutos-Vivar F, Raymondos K, Esteban A, Putensen C, Apezteguía C, Hurtado J, Desmery P, Tomicic V, Elizalde J, Abroug F, Arabi Y, Moreno R, Anzueto A, Ferguson ND: Airway pressure release ventilation versus assist-control ventilation: a comparative propensity score and international cohort study. Intensive Care Med 2010, 36:817-827.

10. Faisy C, Mokline A, Sanchez O, Tadié JM, Fagon JY: Effectiveness of acetazolamide for reversal of metabolic alkalosis in weaning COPD patients from mechanical ventilation. Intensive Care Med 2010, 36:859-863.

11. Ksouri H, Balanant PY, Tadié JM, Heraud G, Abboud I, Lerolle N, Novara A Fagon JY, Faisy C: Impact of morbidity and mortality conferences on analysis of mortality and critical events in intensive care practice. Am J Crit Care 2010, 19:135-145; quiz 146

12. See KC, Phua J, Mukhopadhyay A: Monitoring of extubated patients: are routine arterial blood gas measurements useful and how long should patients be monitored in the intensive care unit? Anaesth Intensive Care 2010, 38:96-101.

13. Tong BC, Hanna J, Toloza EM, Onaitis MW, D'Amico TA, Harpole DH, Burfeind WR: Outcomes of video-assisted thoracoscopic decortication. Ann Thorac Surg 2010, 89:220-225.

14. Bach JR, Gonçalves MR, Hamdani I, Winck JC: Extubation of patients with neuromuscular weakness: a new management paradigm. Chest 2010, 137:1033-1039.

15. Aggarwal AN, Agarwal R, Gupta D: Automatic tube compensation as an adjunct for weaning in patients with severe neuroparalytic snake envenomation requiring mechanical ventilation: a pilot randomized study. Respir Care 2009, 54:1697-1702.

16. Nagai S, Fujimoto Y, Kamei H, Nakamura T, Kiuchi T: Noninvasive positive pressure ventilation to prevent respiratory collapse after extubation: clinical case reports. Transplant Proc 2009, 41:3919-3922.

17. Talab HF, Zabani IA, Abdelrahman HS, Bukhari WL, Mamoun I, Ashour MA, Sadeq BB, El Sayed SI: Intraoperative ventilatory strategies for prevention of pulmonary atelectasis in obese patients undergoing laparoscopic bariatric surgery. Anesth Analg 2009, 109:1511-1516.

18. Teixeira C, da Silva NB, Savi A, Vieira SR, Nasi LA, Friedman G, Oliveira RP, Cremonese RV, Tonietto TF, Bressel MA, Maccari JG, Wickert R, Borges LG: Central venous saturation is a predictor of reintubation in difficult-towean patients. Crit Care Med 2010, 38:491-496.

19. Gao XJ, Qin YZ: A study of cough peak expiratory flow in predicting extubation outcome. Zhongguo Wei Zhong Bing Ji Jiu Yi Xue 2009, 21:390-393.

20. Cohen J, Shapiro M, Grozovski E, Fox B, Lev S, Singer P: Prediction of extubation outcome: a randomised, controlled trial with automatic tube compensation vs. pressure support ventilation. Crit Care 2009, 13:R21.

21. Peirovifar A, Mahmoodpoor A, Naderpoor M, Agamohammadi D: A prospective study of the safety of tracheal extubation using endotracheal ventilation catheter in patients undergoing maxillofacial surgery. Saudi Med J 2009, 30:219-223.

22. Taniguchi C, Eid RC, Saghabi C, Souza R, Silva E, Knobel E, Paes AT, Barbas CS: Automatic versus manual pressure support reduction in the weaning of post-operative patients: a randomised controlled trial. Crit Care 2009, 13:R6.

23. Michelet P, D'Journo XB, Seinaye F, Forel JM, Papazian L, Thomas P: Noninvasive ventilation for treatment of postoperative respiratory failure after oesophagectomy. Br J Surg 2009, 96:54-60.

24. Zarbock A, Mueller E, Netzer S, Gabriel A, Feindt P, Kindgen-Milles D: Prophylactic nasal continuous positive airway pressure following cardiac surgery protects from postoperative pulmonary complications: a prospective, randomized, controlled trial in 500 patients. Chest 2009 135:1252-1259.

25. Schönhofer B, Kuhlen R, Neumann P, Westhoff M, Berndt C, Sitter H: Noninvasive ventilation as treatment for acute respiratory insufficiency. Essentials from the new S3 guidelines. Anaesthesist 2008, 57:1091-1102.

26. Navalesi P, Frigerio P, Moretti MP, Sommariva M, Vesconi S, Baiardi P, Levati A: Rate of reintubation in mechanically ventilated neurosurgical and neurologic patients: evaluation of a systematic approach to weaning and extubation. Crit Care Med 2008, 36:2986-2992

27. Teixeira C, Frederico Tonietto T, Cadaval Gonçalves S, Viegas Cremonese R, Pinheiro de Oliveira R, Savi A, Silvestre Oliveira E, André Cardona Alves F, Fernando Monteiro Brodt S, Hervê Diel Barth J, Santana Machado A, de Campos Balzano P, Gasparetto Maccari J, Brandão Da Silva N: Noradrenaline use is not associated with extubation failure in septic patients. Anaesth Intensive Care 2008, 36:385-390.

28. Lauruschkat AH, Arnrich B, Albert AA, Walter JA, Amann B, Rosendahl UP, Alexander T, Ennker J: Diabetes mellitus as a risk factor for pulmonary complications after coronary bypass surgery. J Thorac Cardiovasc Surg 2008 135:1047-1053.

29. Robertson TE, Sona C, Schallom L, Buckles M, Cracchiolo L, Schuerer D, Coopersmith CM, Song F, Buchman TG: Improved extubation rates and earlier liberation from mechanical ventilation with implementation of a daily spontaneous-breathing trial protocol. J Am Coll Surg 2008 206:489-495

30. Vidotto MC, Sogame LC, Calciolari CC, Nascimento OA, Jardim JR: The prediction of extubation success of postoperative neurosurgical patients using frequency-tidal volume ratios. Neurocrit Care 2008, 9:83-89.

31. Chen XF, Ye JL: Efficacy and safety of non-invasive positive pressure 
ventilation in the care of dyspnea after cardiac surgery. Zhongguo Wei Zhong Bing Ji Jiu Yi Xue 2007, 19:542-545.

32. Bouza C, Garcia E, Diaz M, Segovia E, Rodriguez I: Unplanned extubation in orally intubated medical patients in the intensive care unit: a prospective cohort study. Heart Lung 2007, 36:270-276.

33. Lee $\mathrm{CH}$, Peng MJ, Wu CL: Dexamethasone to prevent postextubation airway obstruction in adults: a prospective, randomized, double-blind, placebo-controlled study. Crit Care 2007, 11:R72.

34. Parker M, Loewen M, Sullivan T, Yatco E, Cerabona T, Savino JA, Kaul A: Predictors of outcome after obesity surgery in New York state from 1991 to 2003. Surg Endosc 2007, 21:1482-1486.

35. Matić I, Danić D, Majerić-Kogler V, Jurjević M, Mirković I, Mrzljak Vucinić N: Chronic obstructive pulmonary disease and weaning of difficult-to-wean patients from mechanical ventilation: randomized prospective study. Croat Med J 2007, 48:51-58.

36. Gowardman JR, Huntington D, Whiting J: The effect of extubation failure on outcome in a multidisciplinary Australian intensive care unit. Crit Care Resusc 2006, 8:328-333.

37. Yap CH, Zimmet A, Mohajeri M, Yii M: Effect of obesity on early morbidity and mortality following cardiac surgery. Heart Lung Circ 2007, 16:31-36.

38. Bamgbade OA, Rutter TW, Nafiu OO, Dorje P: Postoperative complications in obese and nonobese patients. World J Surg 2007, 31:556-560; discussion 561.

39. Lellouche F, Mancebo J, Jolliet P, Roeseler J, Schortgen F, Dojat M, Cabello B, Bouadma L, Rodriguez P, Maggiore S, Reynaert M, Mersmann S, Brochard L: A multicenter randomized trial of computer-driven protocolized weaning from mechanical ventilation. Am J Respir Crit Care Med 2006, 174:894-900.

40. El-Solh AA, Aquilina A, Pineda L, Dhanvantri V, Grant B, Bouquin P: Noninvasive ventilation for prevention of post-extubation respiratory failure in obese patients. Eur Respir J 2006, 28:588-595.

41. Cohen JD, Shapiro M, Grozovski E, Lev S, Fisher H, Singer P: Extubation outcome following a spontaneous breathing trial with automatic tube compensation versus continuous positive airway pressure. Crit Care Med 2006, 34:682-686.

42. Cense HA, Lagarde SM, de Jong K, Omloo JM, Busch OR, Henny ChP, van Lanschot JJ: Association of no epidural analgesia with postoperative morbidity and mortality after transthoracic esophageal cancer resection. J Am Coll Surg 2006, 202:395-400.

43. Rabinstein AA, Mueller-Kronast $\mathrm{N}$ : Risk of extubation failure in patients with myasthenic crisis. Neurocrit Care 2005, 3:213-215.

44. Caruso P, Denari SD, Ruiz SA, Bernal KG, Manfrin GM, Friedrich C, Deheinzelin $D$ : Inspiratory muscle training is ineffective in mechanically ventilated critically ill patients. Clinics (Sao Paulo) 2005, 60:479-484.

45. Ezingeard E, Diconne E, Guyomarc'h S, Venet C, Page D, Gery P, Vermesch R, Bertrand M, Pingat J, Tardy B, Bertrand JC, Zeni F: Weaning from mechanical ventilation with pressure support in patients failing a T-tube trial of spontaneous breathing. Intensive Care Med 2006, 32:165-169.

46. Bercault N, Wolf M, Runge I, Fleury JC, Boulain T: Intrahospital transport of critically ill ventilated patients: a risk factor for ventilator-associated pneumonia--a matched cohort study. Crit Care Med 2005, 33:2471-2478,

47. Nava S, Gregoretti C, Fanfulla F, Squadrone E, Grassi M, Carlucci A, Beltrame F, Navalesi P: Noninvasive ventilation to prevent respiratory failure after extubation in high-risk patients. Crit Care Med 2005, 33:2465-2470.

48. Lauruschkat AH, Arnrich B, Albert AA, Walter JA, Amann B, Rosendahl UP, Alexander T, Ennker J: Prevalence and risks of undiagnosed diabetes mellitus in patients undergoing coronary artery bypass grafting. Circulation 2005, 112:2397-2402.

49. Kindgen-Milles D, Müller E, Buhl R, Böhner H, Ritter D, Sandmann W, Tarnow J: Nasal-continuous positive airway pressure reduces pulmonary morbidity and length of hospital stay following thoracoabdominal aortic surgery. Chest 2005, 128:821-828

50. Krinsley JS, Barone JE: The drive to survive: unplanned extubation in the ICU. Chest 2005, 128:560-566

51. Bumroongkit C, Liwsrisakun C, Deesomchok A, Theerakittikul T, Pothirat C: Efficacy of weaning protocol in medical intensive care unit of tertiary care center. J Med Assoc Thai 2005, 88:52-57.

52. Bingol H, Cingoz F, Balkan A, Kilic S, Bolcal C, Demirkilic U, Tatar H: The effect of oral prednisolone with chronic obstructive pulmonary disease undergoing coronary artery bypass surgery. J Card Surg 2005, 20:252-256.

53. Ponnudurai RN, Koneru B, Akhtar SA, Wachsberg RH, Fisher A, Wilson DJ, de la Torre AN: Vasopressor administration during liver transplant surgery and its effect on endotracheal reintubation rate in the postoperative period: a prospective, randomized, double-blind, placebo-controlled trial. Clin Ther 2005, 27:192-198.

54. Vermes E, Demaria RG, Martineau R, Cartier R, Pellerin M, Hébert Y, Bouchard D, Pagé P, Carrier M, Perrault LP: Increased early postoperative morbidity with off-pump coronary artery bypass grafting surgery in patients with diabetes. Can J Cardiol 2004, 20:1461-1465.

55. Esteban A, Frutos-Vivar F, Ferguson ND, Arabi Y, Apezteguía C, González M, Epstein SK, Hill NS, Nava S, Soares MA, D'Empaire G, Alía I, Anzueto A: Noninvasive positive-pressure ventilation for respiratory failure after extubation. N Engl J Med 2004, 350:2452-2460.

56. Dries DJ, McGonigal MD, Malian MS, Bor BJ, Sullivan C: Protocol-driven ventilator weaning reduces use of mechanical ventilation, rate of early reintubation, and ventilator-associated pneumonia. J Trauma 2004, 56:943951; discussion 951-952.

57. Mori T, Yoshioka M, Watanabe K, Iwatani K, Kobayashi H, Terasaki H, Kawasuji $\mathrm{M}$ : Changes in respiratory condition after thymectomy for patients with myasthenia gravis. Ann Thorac Cardiovasc Surg 2003, 9:93-97.

58. Martinez A, Seymour C, Nam M: Minute ventilation recovery time: a predictor of extubation outcome. Chest 2003, 123:1214-1221.

59. Dimick JB, Pronovost PJ, Cowan JA, Lipsett PA: Surgical volume and quality of care for esophageal resection: do high-volume hospitals have fewer complications? Ann Thorac Surg 2003, 75:337-341.

60. Phoa LL, Pek WY, Syap W, Johan A: Unplanned extubation: a local experience. Singapore Med J 2002, 43:504-508.

61. Luo H, Cheng P, Zhou R: Sequential BiPAP following invasive mechanical ventilation in COPD patients with hypercapnic respiratory failure. Hunan $Y_{i}$ Ke DaXue Xue Bao 2001, 26:563-565.

62. Dimick JB, Pronovost PJ, Cowan JA Jr., Lipsett PA: Postoperative complication rates after hepatic resection in Maryland hospitals. Arch Surg 2003, 138:41-46.

63. Chen CZ, Chu YC, Lee CH, Chen CW, Chang HY, Hsiue TR: Factors predicting reintubation after unplanned extubation. J Formos Med Assoc 2002, 101:542-546.

64. Fagevik Olsén M, Wennberg E, Johnsson E, Josefson K, Lönroth H, Lundell L: Randomized clinical study of the prevention of pulmonary complications after thoracoabdominal resection by two different breathing techniques. BrJ Surg 2002, 89:1228-1234.

65. Cohen JD, Shapiro M, Grozovski E, Singer P: Automatic tube compensationassisted respiratory rate to tidal volume ratio improves the prediction of weaning outcome. Chest 2002, 122:980-984.

66. Dimick JB, Pronovost PJ, Cowan JA, Ailawadi G, Upchurch GR Jr:: The volumeoutcome effect for abdominal aortic surgery: differences in case-mix or complications? Arch Surg 2002, 137:828-832.

67. Keenan SP, Powers C, McCormack DG, Block G: Noninvasive positivepressure ventilation for postextubation respiratory distress: a randomized controlled trial. JAMA 2002, 287:3238-3244

68. Dupont H, Le Port Y, Paugam-Burtz C, Mantz J, Desmonts M: Reintubation after planned extubation in surgical ICU patients: a case-control study. Intensive Care Med 2001, 27:1875-1880

69. Chan PK, Fischer S, Stewart TE, Hallett DC, Hynes-Gay P, Lapinsky SE, MacDonald R, Mehta S: Practising evidence-based medicine: the design and implementation of a multidisciplinary team-driven extubation protocol. Crit Care 2001, 5:349-354.

70. Dimick JB, Swoboda SM, Pronovost PJ, Lipsett PA: Effect of nurse-to-patient ratio in the intensive care unit on pulmonary complications and resource use after hepatectomy. Am J Crit Care 2001, 10:376-382.

71. Filaire M, Mom T, Laurent S, Harouna Y, Naamee A, Vallet L, Normand B, Escande G: Vocal cord dysfunction after left lung resection for cancer. Eur J Cardiothorac Surg 2001, 20:705-711.

72. Dimick JB, Pronovost PJ, Heitmiller RF, Lipsett PA: Intensive care unit physician staffing is associated with decreased length of stay, hospital cost, and complications after esophageal resection. Crit Care Med 2001, 29:753-758.

73. Siegenthaler MP, Pisters KM, Merriman KW, Roth JA, Swisher SG, Walsh GL, Vaporciyan AA, Smythe WR, Putnam JB Jr.: Preoperative chemotherapy for lung cancer does not increase surgical morbidity. Ann Thorac Surg 2001, 71:1105-1111: discussion 1111-1112

74. Abt PL, Patel HJ, Marsh A, Schwartz SI: Analysis of thymectomy for myasthenia gravis in older patients: a 20-year single institution experience. J Am Coll Surg 2001, 192:459-464. 
75. Namen AM, Ely EW, Tatter SB, Case LD, Lucia MA, Smith A, Landry S, Wilson JA, Glazier SS, Branch CL, Kelly DL, Bowton DL, Haponik EF: Predictors of successful extubation in neurosurgical patients. Am J Respir Crit Care Med 2001, 163 (3 Pt 1):658-664

76. Koh Y, Hong SB, Lim CM, Lee SD, Kim WS, Kim DS, Kim WD: Effect of an additional 1-hour T-piece trial on weaning outcome at minimal pressure support. J Crit Care 2000, 15:41-45.

77. Engoren M, Buderer NF, Zacharias A, Habib RH: Variables predicting reintubation after cardiac surgical procedures. Ann Thorac Surg 1999, 67:661-665

78. Vallverdú I, Calaf N, Subirana M, Net A, Benito S, Mancebo J: Clinical characteristics, respiratory functional parameters, and outcome of a twohour T-piece trial in patients weaning from mechanical ventilation. Am J Respir Crit Care Med 1998, 158:1855-1862.

79. Almassi GH, Schowalter T, Nicolosi AC, Aggarwal A, Moritz TE, Henderson WG, Tarazi R, Shroyer AL, Sethi GK, Grover FL, Hammermeister KE: Atrial fibrillation after cardiac surgery: a major morbid event? Ann Surg 1997, 226:501-511; discussion 511-513.

80. Epstein SK, Ciubotaru RL, Wong JB: Effect of failed extubation on the outcome of mechanical ventilation. Chest 1997, 112:186-192.

81. Kollef MH, Shapiro SD, Silver P, St John RE, Prentice D, Sauer S, Ahrens TS, Shannon W, Baker-Clinkscale D: A randomized, controlled trial of protocoldirected versus physician-directed weaning from mechanical ventilation. Crit Care Med 1997, 25:567-574.

82. Ely EW, Baker AM, Dunagan DP, Burke HL, Smith AC, Kelly PT, Johnson MM, Browder RW, Bowton DL, Haponik EF: Effect on the duration of mechanical ventilation of identifying patients capable of breathing spontaneously. N Engl J Med 1996, 335:1864-1869.

83. Epstein SK, Ciubotaru RL: Influence of gender and endotracheal tube size on preextubation breathing pattern. Am J Respir Crit Care Med 1996, 154 (6 Pt 1):1647-1652.

84. Saura P, Blanch L, Mestre J, Vallés J, Artigas A, Fernández R: Clinical consequences of the implementation of a weaning protocol. Intensive Care Med 1996, 22:1052-1056.
85. Leitch EA, Moran $J$, Grealy B: Weaning and extubation in the intensive care unit. Clinical or index-driven approach? Intensive Care Med 1996, 22:752-759.

86. DeHaven CB, Kirton OC, Morgan JP, Hart AM, Shatz DV, Civetta JM: Breathing measurement reduces false-negative classification of tachypneic preextubation trial failures. Crit Care Med 1996, 24:976-980.

87. Redmond JM, Greene PS, Goldsborough MA, Cameron DE, Stuart RS, Sussman MS, Watkins L Jr., Laschinger JC, McKhann GM, Johnston MV, Baumgartner WA: Neurologic injury in cardiac surgical patients with a history of stroke. Ann Thorac Surg 1996, 61:42-47.

88. Kirton OC, DeHaven CB, Morgan JP, Windsor J, Civetta JM: Elevated imposed work of breathing masquerading as ventilator weaning intolerance. Chest 1995, 108:1021-1025.

89. Epstein SK: Etiology of extubation failure and the predictive value of the rapid shallow breathing index. Am J Respir Crit Care Med 1995, 152:545-549.

90. Torres A, Gatell JM, Aznar E, el-Ebiary M, Puig de la Bellacasa J, González J, Ferrer M, Rodriguez-Roisin R: Re-intubation increases the risk of nosocomial pneumonia in patients needing mechanical ventilation. Am J Respir Crit Care Med 1995, 152:137-141.

91. Brochard L, Rauss A, Benito S, Conti G, Mancebo J, Rekik N, Gasparetto A Lemaire F: Comparison of three methods of gradual withdrawal from ventilatory support during weaning from mechanical ventilation. Am J Respir Crit Care Med 1994, 150:896-903.

doi:10.1186/cc11185

Cite this article as: Krinsley JS, et al:: What is the optimal rate of failed extubation? Critical Care 2012, 16:111. 